AL-MARSHAD: JURNAL ASTRONOMI ISLAM DAN ILMU-ILMU BERKAITAN

ISSN 2442-5729 (print) || ISSN 2598-2559 (online), http://jurnal.umsu.ac.id/index.php/almarshad DOI: https://doi.org/10.30596/jam.v4i1.1934

Published June 2018

\title{
Kalender Cina dalam Tinjauan Historis dan Astronomis
}

\author{
Elva Imeldatur Rohmah
}

Institut Pesantren Sunan Drajat

Email: elvaimeldaturrohmah@gmail.com

\begin{abstract}
Abstrak
Kalender adalah sistem pengorganisasian satuansatuan waktu, untuk tujuan penandaan serta perhitungan waktu dalam jangka panjang. Istilah kalender dalam literatur klasik maupun kontemporer biasa disebut tarikh, takwim, almanak dan penanggalan. Bentuk kalender cukup beragam, antara lain kalender sistem matahari (solar system), kalender sistem bulan (lunar system), dan kalender sistem bulanmatahari (lunar-solar system). Kalender Cina adalah salah satu kalender yang menggunakan sistem bulan-matahari (lunar-solar system). Dalam budaya dan pengetahuan bangsa Tiongkok purba, pembuatan kalender telah dikenal sejak ribuan tahun yang lalu. Penanggalan Cina ini dikenal dengan sebutan kalender rembulan, yin $l i$ atau kalender petani (nong liek) karena diperuntukan bagi upaya untuk mengetahui perubahan musim yang terjadi terhadap siklus di bumi. Praktek ini bertujuan agar manusia bisa mengetahui gejala alam yang sedang dan akan terjadi. Perhitungan tersebut didasarkan pada perhitungan ilmu feng shui, yakni dimensi waktu yang didasarkan dari konsep ilmu astronomi tiongkok purba dan mengacu pengaruh peredaran Matahari dan Bulan terhadap Bumi. Kalender Cina dihitung berdasarkan perhitungan lama bulan mengitari bumi yaitu 29,5 hari. Tarikh ini memang bukan tarikh bulan murni karena di samping berdasarkan peredaran bulan dicocokkan pula dengan peredaran musim yang dipengaruhi letak matahari.
\end{abstract}
Artikel Info
Received:
17 Februari 2018
Revised:
11 Maret 2018
Accepted:
15 Mei 2018

Keyword: Kalender Cina, Historis, Astronomis.
A. Latar Belakang
Panjangnya waktu yang tidak
terbatas berada di luar kekuasaan
manusia. Manusia adalah setitik umur
yang akan sirna dari sejarah ke sejarah, sedangkan waktu yang terus berjalan. Manusia hanya menanti pergantian. Keabadian tidak dapat diukur maupun 
AL-MARSHAD: JURNAL ASTRONOMI ISLAM DAN ILMU-ILMU BERKAITAN

ISSN 2442-5729 (print) || ISSN 2598-2559 (online), http://jurnal.umsu.ac.id/index.php/almarshad DOI: https://doi.org/10.30596/jam.v4i1.1934

Published June 2018

dihitung. Seandainya dapat dihitung, maka akan sia-sia karena manusia akan musnah dengan perjalanan waktu. ${ }^{1}$

Tanpa disadari sebenarnya manusia selalu berjalan dengan putaran waktu di muka bumi sesuai dengan berputarnya bumi dan tata surya yang lain. Sistem tata surya yang terdiri dari delapan planet, bulan, komet (asteroid) yang sering disebut juga tubuh atau anggota benda-benda angkasa, dimana seluruh benda angkasa bergerak secara statis dan dinamis. $^{2}$

Dengan adanya pergantian malam dan siang ini membuktikan bahwa semuanya telah ditentukan, diatur dan disesuaikan dengan posisinya atau porosnya masing-masing. Sebagaimana yang termaktub dalam surat Yunus ayat 6 :

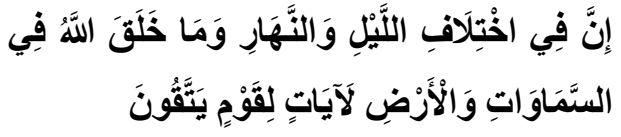

"Sesungguhnya pada pertukaran malam dan siang itu dan pada apa yang diciptakan Allah di langit dan di bumi, benar-benar terdapat tanda-tanda

${ }^{1}$ Slamet Hambali, Almanak Sepanjang Masa, (Semarang : Program Pascasarjana IAIN Walisongo Semarang, 2011), h. 1.

${ }^{2}$ Ibid.
(kekuasaan-Nya) bagi orang-orang yang bertakwa" (QS. Yunus : 6)

Ayat di atas merupakan bukti tentang adanya rotasi bumi. Dan pusat dari benda-benda angkasa atau tata surya adalah matahari. Matahari berputar pada porosnya, dan bumi yang merupakan planet ketiga dari matahari, berputar pada porosnya dalam jangka waktu kurang lebih 24 jam. Inilah yang menyebabkan pergantian siang dan malam. Selain berputar pada porosnya, bumi juga berputar mengelilingi matahari atau dalam perjalanannya disebut revolusi. Jalur bumi untuk mengitari matahari dinamakan orbit. ${ }^{4}$ Dalam surat Yunus ayat 5 diterangkan :

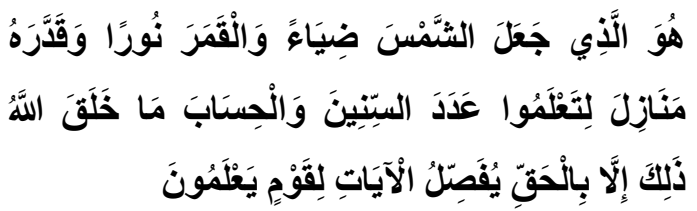
"Dialah yang menjadikan matahari bersinar, bulan bercahaya dan ditetapkannya manzilah-manzilah bagi perjalanan bulan itu, supaya kamu mengetahui bilangan tahun dan diperhitungkan" (QS. Yunus : 5)

3 Departemen Agama RI, Al-Qur'an dan Terjemahannya, (Bandung : J-ART 2005), h. 209.

${ }^{4}$ Slamet Hambali, op.cit., h. 2.

${ }^{5}$ Departemen Agama RI, loc. cit. 
AL-MARSHAD: JURNAL ASTRONOMI ISLAM DAN ILMU-ILMU BERKAITAN

ISSN 2442-5729 (print) || ISSN 2598-2559 (online), http://jurnal.umsu.ac.id/index.php/almarshad DOI: https://doi.org/10.30596/jam.v4i1.1934

Published June 2018

Dari sini kita ketahui bahwa roda kehidupan akan selalu silih berganti, sesuai dengan pergantian siang dan malam. Manusia pun akan mengalami perubahan dengan adanya perubahan tersebut menandakan bahwa alam semesta tidak ada batasan dan hanya Allah yang Maha Tahu Segalanya. ${ }^{6}$

\section{A. Definisi Kalender}

Istilah kalender berasal dari bahasa Inggris modern "calendar", berasal dari bahasa Perancis lama "calendier" yang asal mulanya dari bahasa Latin "kalendarium" yang artinya buku catatan pemberi pinjaman uang. Pada bahasa Latinnya sendiri kalendarium berasal dari kalendae atau calendae yang artinya "hari permulaan suatu bulan". Padanan kalender dalam bahasa Indonesia adalah penanggalan. Adapun menurut istilah, kalender dimaknai sebagai suatu tabel atau deret halaman-halaman yang memperlihatkan hari, pekan dan bulan dalam satu tahun tertentu. $^{7}$

$\begin{array}{ccc}\text { Menurut } & \text { Susiknan } & \text { Azhari } \\ \text { kalender } & \text { adalah } & \text { sistem } \\ \text { pengorganisasian } & \text { satuan-satuan } & \text { waktu, }\end{array}$

${ }^{6}$ Slamet Hambali, op. cit., h. 3.

${ }^{7}$ Ruswa Darsono, Penanggalan Islam, Tinjauan Sistem, Fiqh dan Hisab Penanggalan, (Yogyakarta: Labda Press 2010), h. 27. untuk tujuan penandaan serta perhitungan waktu dalam jangka panjang. ${ }^{8}$ Istilah kalender dalam literatur klasik maupun kontemporer biasa disebut tarikh, takwim, almanak dan penanggalan. ${ }^{9}$

Menurut Slamet Hambali, kalender atau almanak adalah sebuah sistem perhitungan yang bertujuan untuk pengorganisasian waktu dalam periode tertentu. Bulan adalah sebuah unit yang merupakan bagian dari kalender. Hari adalah unit terkecil dari kalender, lalu sitem waktu yaitu jam, menit, dan detik. ${ }^{10}$

Bentuk kalender cukup beragam, bahkan dalam perhitungannya mempunyai aturan siklus sendiri. Di samping itu, ada juga kalender yang memiliki ciri-ciri tersendiri. Dari banyaknya bentuk kalender, setidaknya dapat dibedakan menjadi tiga macam yakni :

1. Kalender sistem matahari (solar system)

${ }^{8}$ Susiknan Azhari, Ensiklopedi Hisab Rukyat, (Yogyakarta: Pustaka Pelajar 2008), h. 115.

${ }^{9}$ Susiknan Azhari, Kalender Islam ke Arah Integrasi Muhammadiyah-NU, (Yogyakarta : Museum Astronomi Islam, 2012), h. 27.

${ }^{10}$ Slamet Hambali, op. cit., h. 3. 
Kalender ini pada prinsipnya menggunakan perjalanan bumi ketika berevolusi atau mengorbit matahari. Ada dua pertimbangan yang digunakan sistem ini : Pertama, adanya pergantian siang dan malam. Kedua, adanya pergantian musim diakibatkan karena orbit yang berbentuk elips ketika mengelilingi matahari. ${ }^{11}$ Kalender yang menggunakan sistem ini antara lain kalender Mesir Kuno, kalender Romawi Kuno, kalender Maya, kalender Julian, kalender Gregorius, dan kalender Jepang. ${ }^{12}$

2. Kalender sistem bulan (lunar system)

Kalender ini menggunakan sistem bulan, artinya perjalanan bulan ketika mengorbit bumi (berevolusi terhadap bumi). Kalender ini murni menggunakan lunar disebabkan karena mengikuti fase bulan. Kalender sistem lunar, pada sisi lain tidak berpengaruh terhadap perubahan musim. Sebab kemunculan bulan dalam satu tahun selama dua belas kali amat mudah diamati. ${ }^{13}$ Kalender yang menggunakan sistem ini antara lain kalender Hijriyah, kalender Saka, dan kalender Jawa Islam. ${ }^{14}$

3. Kalender sistem bulan-matahari (lunar-solar system)

Kalender ini menggunakan bulan-matahari, artinya perjalanan sistem bulan dan matahari di kalender pertama memang berdasarkan atas peredaran bulan. Namun ini memang tidak akurat dengan peredaran bumi mengelilingi matahari. Matahari kemudian menjadi dasar untuk waktu penanggalan (solar) karena sistem peredaran bulan (lunar) tidak cocok dengan bumi mengelilingi matahari. ${ }^{15}$

Pada awalnya, baik sistem lunar maupun solar merupakan gabungan. Namun, belakangan ini sistem kalender lunar dan solar menjadi berdiri sendiri. Pada perayaan-perayaan agama, sistem lunar misalnya dijadikan sebagai petunjuk, seperti pada Crhistian

\footnotetext{
${ }^{11}$ Ibid., h. 3-4.

12 Ibid., h. 4-12.
} 
AL-MARSHAD: JURNAL ASTRONOMI ISLAM DAN ILMU-ILMU BERKAITAN

ISSN 2442-5729 (print) || ISSN 2598-2559 (online), http://jurnal.umsu.ac.id/index.php/almarshad DOI: https://doi.org/10.30596/jam.v4i1.1934

Published June 2018

Easter. Diawali pada agama Hindu dan Yom Kippur di agama Yahudi, demikian pula dengan hari-hari raya Islam. Jadi pada perayaan-perayaan agama banyak mengambil sistem lunar, sedangkan untuk sistem bisnis dan catatan administrasi banyak menggunakan sistem solar. ${ }^{16}$ Kalender yang menggunakan sistem ini antara lain kalender Babilonia, kalender Yahudi, dan kalender Cina. ${ }^{17}$

\section{B. Sejarah Kalender Cina}

Orang-orang telah tinggal di pemukiman di Cina setidaknya sejak 3500 SM. Meskipun terdapat cerita tradisional seperti itu, tanggal penulisan paling awal dikenal sejak periode Shang (sekitar 1600 SM). Cina merupakan daerah yang luas dan bervariasi. Berikut ini adalah tabel dari beberapa peristiwa penting dalam sejarah Cina: ${ }^{18}$

\begin{tabular}{|c|l|}
\hline Tahun & \multicolumn{1}{|c|}{ Peristiwa } \\
\hline $3500 \mathrm{SM}$ & Budaya Long Shan \\
\hline $2000 \mathrm{SM}$ & Dinasti He \\
\hline $1600 \mathrm{SM}$ & Zaman Perunggu \\
\hline
\end{tabular}

${ }^{16}$ Ibid., h. 19.

${ }^{17}$ Ibid., h. 19-23.

18 Richards E.G, Mapping Time : The Calendar and Its History, (Newyork : Oxford University Press, 1998), h, 161-162.

\begin{tabular}{|c|c|}
\hline & Dinasti Shang \\
\hline 1045 SM & Dinasti Zhou \\
\hline $771 \mathrm{SM}$ & $\begin{array}{l}\text { Runtuhnya } \\
\text { pemerintah feodal } \\
\text { Zhou Barat }\end{array}$ \\
\hline 453-221 SM & Negara berperang \\
\hline $221 \mathrm{SM}$ & Dinasti Qin \\
\hline 202 SM & Dinasti Han \\
\hline $9 \mathrm{M}$ & $\begin{array}{l}\text { Wang Mang } \\
\text { melengserkan Dinasti } \\
\text { Han }\end{array}$ \\
\hline $25 \mathrm{M}$ & $\begin{array}{l}\text { Pemulihan Dinasti } \\
\text { Han }\end{array}$ \\
\hline $220 \mathrm{M}$ & Akhir Dinasti Han \\
\hline $589 \mathrm{M}$ & Dinasti Sui \\
\hline $618 \mathrm{M}$ & Dinasti Tang \\
\hline $907 \mathrm{M}$ & $\begin{array}{l}\text { Kaisar Tang terakhir } \\
\text { digulingkan }\end{array}$ \\
\hline $947 \mathrm{M}$ & Dinasti Liao \\
\hline $960 \mathrm{M}$ & Dinasti Song \\
\hline $1271 \mathrm{M}$ & $\begin{array}{l}\text { Dinasti Yuan (Kublai } \\
\text { Khan) }\end{array}$ \\
\hline $1275-1291$ & $\begin{array}{l}\text { Kunjungan Marco } \\
\text { Polo }\end{array}$ \\
\hline $1368 \mathrm{M}$ & Dinasti Ming \\
\hline $1595 \mathrm{M}$ & $\begin{array}{l}\text { Misi Yahudi di } \\
\text { Tiongkok }\end{array}$ \\
\hline $1644 \mathrm{M}$ & $\begin{array}{l}\text { Dinasti Qing } \\
\text { (Manchu) }\end{array}$ \\
\hline $1911 \mathrm{M}$ & Revolusi (Sun Yat \\
\hline
\end{tabular}


AL-MARSHAD: JURNAL ASTRONOMI ISLAM DAN ILMU-ILMU BERKAITAN

ISSN 2442-5729 (print) || ISSN 2598-2559 (online), http://jurnal.umsu.ac.id/index.php/almarshad DOI: https://doi.org/10.30596/jam.v4i1.1934

Published June 2018

\begin{tabular}{|l|l|}
\hline & Sen) \\
\hline $1926 \mathrm{M}$ & Chiang Kai Shek \\
\hline $1949 \mathrm{M}$ & $\begin{array}{l}\text { Kemenangan } \\
\text { Komunis }\end{array}$ \\
\end{tabular}

Dalam budaya dan pengetahuan bangsa Tiongkok purba, pembuatan kalender telah dikenal sejak ribuan tahun yang lalu. Penanggalan ini dikenal dengan sebutan kalender rembulan, yin li atau kalender petani (nong liek) karena diperuntukan bagi upaya untuk mengetahui perubahan musim yang terjadi terhadap siklus di Bumi. Praktek ini bertujuan agar manusia bisa mengetahui gejala alam yang sedang dan akan terjadi. Perhitungan tersebut didasarkan pada perhitungan ilmu feng shui, yakni dimensi waktu yang didasarkan dari konsep ilmu astronomi tiongkok purba dan mengacu pengaruh peredaran Matahari dan Bulan terhadap Bumi. ${ }^{19}$

Selama 2000 tahun Periode Kekaisaran Cina, permasalahan kalender ditanggapi dengan sangat serius di Pengadilan Kekaisaran, sehingga jabatan pembuat kalender menjadi jabatan yang bergengsi pada saat itu. Pembuat kalender memiliki

${ }^{19}$ Mas Dian, MRE, Tong Shu Almanak, (Semarang : PT. Elexmedia, 2002), h. 1. tanggung jawab mempersiapkan almanak yang akan memberikan -selain rincian kalender dan berbagai item astronomi- ramalan tahunan dan ritual yang harus dilakukan untuk menghindari malapetaka. Pembuatannya menuntut keterampilan yang luar biasa terlepas dari kemampuan untuk memahami detail rumit dari kalender itu sendiri. Selalu ada bahaya dalam hal ini karena pembuat kalender akan dieksekusi jika dia salah. Pemerintah kemudian menyebarkan kalender ke seluruh Kekaisaran dan memastikan bahwa kalender palsu tidak tersebar. ${ }^{20}$

Dalam sejarah Cina ada faham yang mempelajari perhitungan waktuwaktu serta bulan-bulan yang bertujuan agar selaras dengan dengan tenagatenaga alam. Perhitungan ini terkemas dalam kalender/almanak kecil yaitu dalam sejarah cina dinamakan faham madzhab Yin-Yang. Karena itu mazhab Yin-Yang menghubungkan keempat musim dari keempat mata angin yaitu musim panas dihubungkan dengan selatan, musim dingin dengan utara, musim semi dengan timur, musim gugur dengan barat. Paham ini yang

${ }^{20}$ Richards E.G, op. cit., h. 162. 
juga memandang perubahan siang dan malam dalam skala kecil yang mencerminkan perubahan keempat musim dalam satu tahun yaitu skala kecil musim semi: siang mencerminkan musim panas, malam mencerminkan musim gugur, larut malam mencerminkan musim dingin. ${ }^{21}$

Perlu ditegaskan pula bahwa penjabaran almanak Tong Shu bukanlan ramalan yang bersifat mistik, akan tetapi berdasarkan perhitungan yang sangat rumit dan rumusan yang bersifat matematis yang didasarkan pada pengamatan pergerakan alam semesta (Matahari, Bulan dan planet-planet lainnya) terhadap gravitasi dan magnetik yang ada di Bumi. Hal di atas dimaksudkan untuk kepentingan perkawinan, buka usaha, terima jabatan, penguburan dan lain sebagainya. ${ }^{22}$

Sistem penghitungan Cina adalah desimal dan ini tercermin dalam beberapa subdivisi kalender mereka. Terdapat 10 ekspresi yang ditemukan dalam lima prinsip surgawi atau elemen : logam, kayu, air, api, dan bumi. Masing-masing dapat terwujud dalam

21 Suejono Suemargono, Sejarah Ringkas Filsafat Cina, (Yogyakarta: Liberty, tt ), h. 176-177.

${ }^{22}$ Mas Dian, MRE, op.cit., h. 1. bentuk Yin dan Yang, sehingga keseluruhannya menjadi 10. Prinsipprinsip yang berlawanan dari Yin dan Yang, dan rekonsiliasi mereka, memainkan peranan yang penting dalam pemikiran Cina. Yin adalah laki-laki dan terkait dengan panas dan siang hari, sedangkan Yang adalah perempuan dan terkait dengan dingin dan malam. ${ }^{23}$

Pada saat penggalian arkeologi di Anyang dekat Sungai Kuning ditemukan ribuan tulang, terutama tulang belikat lembu dan cangkang kura-kura. Penemuan mereka disebut 'tulang peramal' yang menunjukkan bahwa tulang-tulang ini terkubur pada masa dinasti Shang. Tulang-tulang ini digunakan sebagai media untuk meramal dengan cara memanaskan tulang-tulang tersebut hingga retakan muncul, yang kemudian retakan tersebut ditafsirkan sebagai jawaban dari Dewa. Dalam tulang-tulang tersebut juga tertulis tanggal dan catatan pembayaran upeti. Penemuan ini telah memberikan banyak informasi tentang kalender Cina awal 1400 SM. ${ }^{24}$

Tulang peramal Shang memberikan bukti bahwa orang Cina

\footnotetext{
${ }^{23}$ Richards E.G, op. cit., h. 162.

${ }^{24}$ Ibid., 162-163.
} 
pada waktu itu percaya bahwa satu tahun adalah 3651/4 hari dan satu bulan adalah 291/2 hari. Hal ini menghasilkan pembagian lingkaran, bukan menjadi 360 derajat dalam cara Babilonia, tetapi menjadi 365 derajat Cina. Dengan demikian matahari bergerak memutari Ekliptika sekitar satu derajat setiap hari. $^{25}$

\section{Siklus Sexagesimal}

Tulang peramal Shang menunjukkan bahwa, pada saat mereka digunakan sekitar 1.400 SM, hari (dalam 10 dan 12 siklus hari) dihitung selama periode seksagesimal 60 hari, 60 adalah kelipatan umum terendah dari 10 dan 12. Hari-hari dalam siklus 10 hari diberi nama 'the ten heavenly stems' dan siklus 12 hari disebut the twelve earthly branches'. Siklus 60 hari dibagi lagi menjadi enam dekade 10 hari, masing-masing dimulai dengan cabang pertama yang dikenal sebagai ' $z i$ ', dari hari pertama siklus. ${ }^{26}$

Dimulai dari dinasti Zhou dan seterusnya, tahun-tahun juga dihitung dengan cara ini menggunakan nama yang sama. Meskipun praktik penamaan hari sudah tidak ada lagi atau tidak

${ }^{25}$ Ibid., 163.

${ }^{26}$ Ibid., h. 163. berlaku, namun penamaan tahun masih tetap berjalan. Pada abad ini, 'the twelve earthly branches' sangat menonjol sebagai nama tahun. Tahun 2000 misalnya, adalah tahun naga. Namanama dari 'the ten heavenly stems' dan 'the twelve earthly branches' bisa dilihat pada tabel di bawah ini: ${ }^{27}$

\begin{tabular}{|c|c|c|}
\hline \multicolumn{3}{|c|}{ The Ten Heavenly Stems } \\
\hline Nomor & $\begin{array}{c}\text { Nama } \\
\text { Cina }\end{array}$ & Makna \\
\hline 1 & Jia & $\begin{array}{c}\text { Kayu yang } \\
\text { tumbuh }\end{array}$ \\
\hline 2 & Yi & Potongan kayu \\
\hline 3 & Bing & Api alami \\
\hline 4 & Ding & Api buatan \\
\hline 5 & Wu & Bumi \\
\hline 6 & Ji & Tembikar \\
\hline 7 & Geng & Logam \\
\hline 8 & Xin & Logam tempa \\
\hline 9 & Ren & Air mengalir \\
\hline 10 & Gui & Air mancur \\
\hline
\end{tabular}

\section{The Twelve Earthly Branches}

\begin{tabular}{|c|c|c|}
\hline Nomor & $\begin{array}{c}\text { Nama } \\
\text { Cina }\end{array}$ & Makna/Shio \\
\hline 1 & $Z i$ & Tikus \\
\hline 2 & Chou & Kerbau \\
\hline 3 & Yin & Harimau \\
\hline
\end{tabular}

${ }^{27}$ Ibid., h. 163-164. 
AL-MARSHAD: JURNAL ASTRONOMI ISLAM DAN ILMU-ILMU BERKAITAN

ISSN 2442-5729 (print) || ISSN 2598-2559 (online), http://jurnal.umsu.ac.id/index.php/almarshad DOI: https://doi.org/10.30596/jam.v4i1.1934

Published June 2018

\begin{tabular}{|c|c|c|}
\hline 4 & Mao & Kelinci \\
\hline 5 & Chen & Naga \\
\hline 6 & $S i$ & Ular \\
\hline 7 & $W u$ & Kuda \\
\hline 8 & $W e i$ & Domba \\
\hline 9 & Shen & Monyet \\
\hline 10 & You & Ayam jantan \\
\hline 11 & Xu & Anjing \\
\hline 12 & $\mathrm{Hal}$ & Babi \\
\hline
\end{tabular}

Dua belas hewan (shio) ini secara

bergiliran dipengaruhi oleh lima unsur : tanah, logam, air, kayu, dan api. Masing-masing unsur akan berpengaruh selama dua tahun. Dengan demikian, kombinasi suatu unsur dengan hewan tertentu akan berulang setiap siklus besar 60 tahun. ${ }^{28}$

\section{Kalender Cina dalam Tinjauan}

\section{Astronomis}

Kalender Cina disebut sebagai Yin Yang $L i^{29}$ yang berarti Penanggalan Bulan-Matahari (Lunisolar Calendar). Ada juga yang menyebutnya Tarikh Imlik. Sebagian lagi menyebutnya kalender Khongcu Lik/Tarikh Khongcu atau tarikh bulan, karena berdasarkan perhitungan lama bulan mengitari bumi yaitu 29,5 hari. Tarikh ini memang

\footnotetext{
${ }^{28}$ Slamet Hambali, op. cit., h. 24.

29 http://www2.kompas.com/kompascetak/0202/15/IPTEK/imle30.htm
} samping berdasarkan peredaran bulan dicocokkan pula dengan peredaran musim yang dipengaruhi letak matahari. Sehingga penanggalan ini dapat digunakan untuk menentukan bulan baru dan purnama, dapat juga untuk menentukan peredaran musim, maka disebut juga Im Yang Lik (Luni-Solar Calender). ${ }^{30}$

Aturan penanggalannya didasarkan pada revolusi dan rotasi bumi. Dasar perhitungannya adalah $:^{31}$

a. Kala rotasi bumi selama 24 jam

b. Kala revolusi bumi: $365,25 \mathrm{X}$ kala rotasi bumi $=365,25$ hari $=1$ tahun

Adanya angka yang tidak bulat di atas, maka perhitungan tahun dilakukan dengan penetapan. Penanggalan sistem ini telah dimulai sejak zaman kekaisaran Romawi di Eropa pada tahun 47 SM. Penanggalan sistem ini dikenal dengan nama Julian karena perintah dari kaisar Julius Caesar dengan hitungan satu tahun 365 hari 6 jam (365,25 hari). Kelebihan 6 jam tiap tahunnya ditambahkan pada tahun keempat dengan menambahkan 1 hari pada

30 Hendrik Agus Winarso, Mengenal Hari Raya Konfusiani, (Semarang: Efektif \& Harmonis, 2000), h. 55.

${ }^{31}$ Ibid., h. 27-29. 
tahun tersebut. Sehingga tahunnya disebut tahun kabisat yang dapat diketahui dengan membagi bilangan tahun dengan angka 4, jika tidak ada sisa berarti tahun tersebut disebut basithoh. Tambahan ini disebut juga Adhikasuradina.

Namun pada akhir XVI, para ahli kosmologi mengamati adanya keanehan yaitu awal musim semi tidak jatuh pada tanggal 21 maret lagi, tetapi semakin maju. Akhirnya ditemukan kesalahan yaitu kala revolusi bumi 365 hari 5 jam 56 menit, jadi 365 hari 6 jam kurang 4 menit. Maka tahun Julian kelebihan 4 menit tiap tahun. Sehingga Paus Gregorius memberi dua pembetulan terhadap kelebihan menghitung 4 menit.

a. 100 tahun, kelebihan menjadi 400 menit

b. 400 tahun, kelebihan menjadi 1600 menit (26 jam 40 menit atau 1 hari 2 jam 40 menit)

$$
\text { Jadi dengan dilakukan }
$$

pembetulan 1 hari setiap 400 tahun sekali hanya tersisa 2 jam 40 menit setiap 400 tahun. Maka sesudah tanggal 4 Oktober 1582 hari berikutnya adalah 15 oktober 1582, jadi tanggal 5 Oktober sampai 14 Oktober 1582 tidak pernah ada dalam penanggalan Gregorius yang juga dipakai oleh seluruh dunia karena dipakai secara internasional.

Bulan adalah satelit bumi yang berevolusi terhadap bumi dan bersama bumi berevolusi mengelilingi matahari. Kala rotasinya sama dengan kala revolusinya yaitu 27,3 hari yang disebut sideris. Sehingga wajah bulan yang menghadap bumi selalu sama tidak pernah berubah. ${ }^{32}$

Bulan mengelilingi bumi sebanyak 360 derajat. Karena terpengaruh oleh revolusi bumi yang ditempuh selama 27.3 hari, maka setiap harinya bulan beredar $1 / 27,3 \times 360^{\circ}=$ $13,2^{\circ}$ selama 27,3 hari bumi telah beredar menempuh jarak 27,3 derajat karena 1 hari bumi berevolusi satu derajat.

Bulan harus menempuh 27,3 derajat untuk berpindah dari kedudukan bulan purnama pertama sampai purnama berikutnya. Putaran itu ditempuh bulan dalam waktu 27,3/13,2 hari $=2,2$ hari. Jadi dari bulan purnama ke bulan purnama berikutnya memerlukan waktu 27,3 hari $+2,2$ hari yaitu 29,5 hari (rotasi sinodis).

Dari adanya kedua sejarah perbedaan sistem tersebut, para ahli

${ }^{32}$ Ibid., h. 31-33. 
astronomi menemukan kejanggalan dan perbedaan (seperti yang telah dijelaskan di atas). Penanggalan bulan yang merupakan perhitungan yang berdasarkan pada peredaran bulan. Demikian juga untuk perhitungan hari penanggalan matahari yang berjumlah 365 hari tiap tahunnya. Ada perbedaan antara penanggalan surya dan bulan yaitu sekitar 10-11 hari per tahun atau 7 bulan tiap 19 tahun. Penyesuaian kedua sistem penanggalan tersebut dikenal dengan nama Luni Solar Calendaer.

Dalam penanggalan Cina juga dikenal konsep tahun biasa yang terdiri dari 353, 354 atau 355 hari dan tahun kabisat yang terdiri dari 383, 384, atau 385 hari. Perbedaan antara tahun kabisat dan tahun biasa mencapai satu bulan, hal ini berbeda dengan tahun kabisat pada penanggalan Hijriah dan Masehi yang hanya berbeda satu hari dari tahun biasanya. Penambahan satu bulan (leap month) tersebut bisa terjadi pada bulan berapa pun. ${ }^{33}$

Shio adalah simbol binatang Cina yang mewakili 12 siklus tahunan. Mereka mewakili konsep siklus waktu, tidak seperti konsep waktu Barat yang

33 http://www2.kompas.com/kompascetak/0202/15/IPTEK/imle30.htm diwakili oleh bintang-bintang. Kalender bulan Cina dibuat berdasarkan siklus dari bulan, dan dibangun dalam format berbeda dari kalender Barat yang menggunakan matahari. Dalam kalender Cina, awal tahun dimulai antara akhir Januari dan awal Februari. Cina mengadopsi kalender Barat sejak tahun 1911, meskipun kalender lunar masih digunakan untuk acara-acara festival seperti Chinese New Year atau lebih sering dikenal dengan Imlek. ${ }^{34}$

Tahun Cina terdiri atas 12 bulan atau 13 bulan jika Tahun Kabisat dalam 1 bulan terdiri 29 atau 30 hari. Sehingga dalam setahun terdiri dari 355 hari atau 385 hari (Tahun Kabisat). Sehingga pada sistem penanggalan Masehi (Gregorian), Tahun Baru Cina pasti jatuh antara 21 Januari (paling awal) hingga 20 Februari (paling akhir) setiap tahunnya.

Di dalam kalender Cina terdapat tahun Baru Imlik atau Sia Cia yang jatuh pada tanggal satu bulan Cia Gwee atau bulan pertama penanggalan Cina atau Tarikh Khongcu yang merupakan sistem penanggalan dari Dinasti $\mathrm{He}$ (tahun 2205-1766 SM). Perhitungannya berdasarkan pada peredaran bulan dan

\footnotetext{
${ }^{34}$ Slamet Hambali, op. cit., h.24.
} 
matahari. Sistem inilah yang masih dipakai hingga saat ini dan dikenal dengan nama penanggalan Imlik (baca: Imlek). ${ }^{35}$

Sistem penanggalan tersebut dicanangkan untuk dipergunakan kembali oleh nabi Khongcu (menurut kepercayaan mereka) yang hidup pada tahun 551-479 SM. Sehingga tahun pertama dari penanggalan Imlik tersebut dihitung mulai dari tahun kelahiran nabi Khongcu tepatnya pada tanggal 27 bulan delapan Imlik tahun 551 SM sehingga tahun Imlik adalah tahun masehi ditambah 551.

Pada zaman dahulu, telah menjadi tradisi tiap dinasti menggunakan sistem penanggalan yang berbeda. Perbedaan penanggalan ini terutama mengenai tahun barunya.

Dinasti $\mathrm{He}$ menetapkan tahun barunya pada saat Kian Len (saat kejadian manusia), Cia Gwee seperti yang dipakai hingga saat ini. Sedangkan Dinasti Len (1766-1122 SM) menetapkan saat Kian Thio (saat kejadian bumi) yaitu satu Cap Ji Gwee yang sekarang ini. Dan Dinasti Ciu menetapkan pada saat Kian Ciu (saat kejadian langit) yaitu bulan baru Cap It

35 Hendrik Agus Winarso, op. cit., h. 55.
Gwee atau tepatnya pada saat Tang Ce

(22 Desember, Tarikh Masehi). ${ }^{36}$

Dalam penghidupan rakyat jelata zaman dahulu, penetapan tahun baru memegang peranan penting, karena penetapan itu menjadi pedoman mereka untuk menyiapkan pekerjaan tahun mendatang.

Pada zaman kuno tersebut, tidak ada catatan penanggalan yang dimiliki oleh rakyat sendiri, karena tidak ada alat-alat tulis seperti sekarang. Mereka menanti saat-saat tahun baru dari petugas kerajaan. Hal itu dapat dilihat pada kitab Su King bagian kitab Dinasti He. Disana tertulis : "Tiap tahun pada saat datang permulaan musim semi (Bing Cun) diperintahkanlah orang dengan membawa genta logam (Bok Tok) yang dipukul dengan kayu berjalan sepanjang jalan."

Sebagaimana kita ketahui Dinasti He menetapkan tahun barunya pada saat menjelang musim semi, maka utusannya akan dikirim pada saat itu pula. Sedangkan Dinasti Len atau Siang menetapkan tahun barunya pada akhir musim dingin (Kwi Tang).

Sedangkan Dinasti Ciu menetapkan tahun barunya pada 
pertengahan musim dingin atau Tiong

Tang, mereka akan mengutus wakilnya pada bulan yang sesuai dengan penetapannya. Sehingga dapat kita ketahui bahwa Dinasti He lebih bijaksana dalam menetapkan tahun barunya, karena bertepatan dengan persiapan pekerjaan untuk tahun yang akan datang. Sedangkan Dinasti Len dan Ciu, rakyat masih harus melewatkan musim dingin untuk menanti satu atau dua bulan.

Pada tahun 104 SM sistem penanggalan yang disabdakan oleh $\mathrm{Nabi}$ Khongcu yaitu menggunakan sistem penanggalan Dinasti He diresmikan sebagai penanggalan negara. Begitu juga agama Khonghucu dijadikan agama negara.

Demikian sistem penanggalan Dinasti Han tetap digunakan mulai Dinasti Han dan dilanjutkan terus sampai Dinasti Manchu/Bwan Ciи (1911 M). Ketika republik Tiongkok diproklamirkan, sistem penanggalan resmi diubah menjadi Yong Lik. Sampai sekarang penanggalan Khongcu Lik tetap digunakan di beberapa negara di Asia, termasuk perayaan tahun baru
Imlik, hanya berbeda nama untuk masing-masing negara. ${ }^{37}$

Pada saat ini, kalender Cina hanya digunakan untuk menandai perayaan orang Cina, seperti Tahun Baru Cina, perayaan Duan $W u$, dan perayaan Kuih Bulan. Begitu juga dalam bidang astrologi, seperti memilih tahun yang sesuai untuk melangsungkan perkawinan atau meresmikan pembukaan bangunan baru. Sementara itu, untuk kegiatan harian, mayarakat Cina mengacu pada hitungan kalender Masehi. ${ }^{38}$

\section{E. Penutup}

Dari beberapa pembahasan yang telah dipaparkan oleh penulis, dapat ditarik kesimpulan sebagai berikut :

1. Kalender atau almanak adalah sebuah sistem perhitungan yang bertujuan untuk pengorganisasian waktu dalam periode tertentu. Bentuk kalender cukup beragam, antara lain kalender sistem matahari (solar system), kalender sistem bulan (lunar system), dan kalender sistem bulan-matahari (lunar-solar system).

\footnotetext{
${ }^{37}$ Hendrik Agus Winarso, op. cit., h. 55.

${ }^{38}$ Slamet Hambali, op. cit., h. 25-26.
} 
2. Dalam budaya dan pengetahuan bangsa Tiongkok purba, pembuatan kalender telah dikenal sejak ribuan tahun yang lalu. Penanggalan ini dikenal dengan sebutan kalender rembulan, yin li atau kalender petani (nong liek) karena diperuntukan bagi upaya untuk mengetahui perubahan musim yang terjadi terhadap siklus di Bumi. Praktek ini bertujuan agar manusia bisa mengetahui gejala alam yang sedang dan akan terjadi. Perhitungan tersebut didasarkan pada perhitungan ilmu feng shui, yakni dimensi waktu yang didasarkan dari konsep ilmu astronomi tiongkok purba dan mengacu pengaruh peredaran Matahari dan Bulan terhadap Bumi.

3. Kalender Cina dihitung berdasarkan perhitungan lama bulan mengitari bumi yaitu 29,5 hari. Tarikh ini memang bukan tarikh bulan murni karena di samping berdasarkan peredaran bulan dicocokkan pula dengan peredaran musim yang dipengaruhi letak matahari. Sehingga penanggalan ini dapat digunakan untuk menentukan bulan baru dan purnama, dapat juga untuk menentukan peredaran musim, maka disebut juga Im Yang Lik (Luni-Solar Calender). Aturan penanggalannya didasarkan pada revolusi dan rotasi bumi.

\section{Daftar Pustaka}

Azhari, Susiknan. (2008). Ensiklopedi Hisab Rukyat. Yogyakarta: Pustaka Pelajar.

(2012). Kalender Islam ke Arah Integrasi Muhammadiyah-NU. Yogyakarta: Museum Astronomi Islam.

Darsono, Ruswa. (2010). Tinjauan Sistem, Fiqh dan Hisab Penanggalan. Yogyakarta: Labda Press.

Departemen Agama RI. 2005. AlQur'an dan Terjemahannya. Bandung: J-ART.

Dian, Mas, MRE, Tong Shu Almanak (2002). Semarang: PT. Elexmedia.

Hambali, Slamet. (2011). Almanak Sepanjang Masa. Semarang: Program Pascasarjana IAIN Walisongo Semarang.

http://www2.kompas.com/kompascetak/0202/15/IPTEK/imle30.htm 
AL-MARSHAD: JURNAL ASTRONOMI ISLAM DAN ILMU-ILMU BERKAITAN

ISSN 2442-5729 (print) || ISSN 2598-2559 (online), http://jurnal.umsu.ac.id/index.php/almarshad DOI: https://doi.org/10.30596/jam.v4i1.1934

Published June 2018

Richards E.G. (1998) Mapping Time :

The Calendar and Its History.

Newyork: Oxford University Press.

Suemargono, Suejono. Sejarah Ringkas

Filsafat Cina. Yogyakarta: Liberty.

Winarso, Hendrik Agus. (2000)

Mengenal Hari Raya Konfusiani.

Semarang: Efektif \& Harmonis. 